American Journal of Applied Sciences 8 (9): 903-909, 2011

ISSN 1546-9239

(C) 2011 Science Publications

\title{
Distinguishing Congestion and Technical Inefficiency in Presence Undesirable Output
}

\author{
${ }^{1}$ Faranak Hosseinzadeh Saljooghi and ${ }^{2}$ Mohammad Mahallati Rayeni \\ ${ }^{1}$ Department of Mathematics, University of Sistan and Baluchestan, Zahedan, Iran \\ ${ }^{2}$ Department of Management, Technological Institution of Bahonar, Zahedan, Iran
}

\begin{abstract}
Problem statement: This study focuses on problems of congestion and how they might be treated in Universities, also investigates a methodology to measure undesirable outputs congestion in addition to inputs congestion, from both theoretical and empirical perspectives. Congestion indicates an economic state where inputs are overly invested. Evidence of congestion occurs whenever reducing some inputs can increase outputs. Approach: The main thrust of this study is to measure congestion in undesirable outputs and inputs by using Data Envelopment Analysis (DEA), by a proposed linear model. Results: We Using a data set of university and jointly evaluate desirable University output (e.g., graduate) and the simultaneous undesirable output (e.g., dropout) that occurs. Conclusion: The results show that inefficiency is associated with congestion in the study departments of University; particular congestion in undesirable output has most correlation with the efficiency.
\end{abstract}

Key words: Data Envelopment Analysis (DEA), undesirable output, medical science, traffic engineering, technical inefficiency, non-linear programming, Constant Returns to Scale (CRS), marginal product, Decision-Making Units (DMUs)

\section{INTRODUCTION}

Congestion is a term that is applicable in a variety of disciplines which range from medical science to traffic engineering and transmission (Taher and Besharat, 2008). It also has many uses in practical everyday life. In economics, congestion is said to occur when some of the outputs that are maximally possible are reduced by increasing one or more inputs without improving any other input or output. Congestion is a special phenomenon in the production process where excessive amounts of the input cause a reduction of the output; also Congestion can be viewed as an extreme form of technical inefficiency and as such, can be regarded as a potentially serious practical problem.

Mining is a typical example. When too many workers are crowded in a narrow underground mining pit, the amount of minerals excavated will be reduced; also university is another example which excess input cause reduction of outputs. A substantial increase in the ratio of students to academic staff has been a common experience in universities throughout the world in recent decades. As a result, the marginal product of students might have become negative in some universities. The implication of this is that a reduction in the number of students, with all other inputs (staff, buildings) held constant, might raise a university's output in terms of research, consultancy and qualifications awarded, both undergraduate and postgraduate.

Fare et al. (1986) defined different degrees of economic congestion. They suggested a measure of input congestion which is the ratio of two Farrell technical efficiency measures: one measure is computed under weak disposability of inputs, the other one under strong disposability of inputs that is called "FGL". Later, Cooper et al. (2001) introduced an alternative DEA (Data Envelopment Analysis) approach for congestion study. They developed a new DEA-based approach to capture input congestion (CCT approach). DEA is a decisional technique that has been widely used for performance analysis in public and private sectors. In the past three decades, DEA has been developed conceptually and methodologically. DEA is recognized as a suitable tool for measuring of performance (Jahanshahoo et al. 2011; Ashrafi et al. 2011), productivity growth and benchmarking (Rayeni et al., 2010; Rayeni and Saljooghi, 2010; Chen et al., 2010). Another issue that pertains to any output

Corresponding Author: Faranak Hosseinzadeh Saljooghi, Department of Mathematics, University of Sistan and Baluchestan, Zahedan, Iran 
oriented DEA model is congestion which essentially studies redundancy in resource allocations.

Undesirable factors have been grown substantially since Fare et al. (1989) firstly introduced a non-linear programming problem for efficiency evaluation in the existence of undesirable factors. Scheel (2001) proposed some radial measures which assume that any change of the output level will involve both undesirable and desirable outputs.

This study exhibits a DEA model with undesirable outputs then investigates relation these outputs and congestion on the efficiency of education departments.

The study is organized as follows. At the first, we present the notations, assumptions and basic concepts for measuring congestion using DEA and the effect undesirable output in efficiency. Then we focus on the measure of input and undesirable output congestion in departments' education. The results of the empirical analysis will be discussed and in the last, conclusion given at the end.

\section{MATERIALS AND METHODS}

Congestion measurement using Data Envelopment Analysis: For measuring congestion using DEA, at first must calculate efficiency in the based on DEA, because congestion is occurring in inefficient DMUs.

Farrell (1957) proposed to use production frontier or so-called efficiency frontier to measure production efficiency, use "non-preset production function" to replace common "preset production function", regard all Decision-Making Units (DMUs) as one identical production function and use piece-wise to connect the most appropriate DMU points to form an enveloping curve or efficiency frontier regardless of any parameter of population, so as to evaluate technical efficiency and allocative efficiency or price efficiency and define its efficiency value in $0-1$ (the value of 1 indicates it is efficient, otherwise it is inefficient). This theory has primarily three basic hypotheses: (1) production frontier is composed of the most efficient units to evaluate and relatively inefficient units to evaluate fall below this frontier; (2) Constant Returns to Scale (CRS); (3) production frontier convex origin and the slope of every point is not positive.

Charnes et al. (1978) expanded Farrell's efficiency measurement concept of multiple inputs and single output to the concept of multiple inputs and multiple outputs, utilized linear combination to convert it to single virtual input and output, as Data Envelopment Analysis (DEA). DEA is a well-known family of mathematical programming tools for assessing the relative efficiency of a set of comparable processing units, as DMUs. One of the strong points of DEA is its non-parametric character, which means that only the observed inputs consumption values and outputs production amounts are needed in order to properly assess the relative efficiencies of the DMU. The way to do this is extrapolating, from the observed sample of inputs and outputs, a set of possible operating points, assuming some technology. The most common technologies are Constant Return to Scale (CRS) and Variable Return to Scale (VRS), both of which consider linear combinations of the inputs and outputs of the existing DMU. Constant returns to scale assume that there is no significant relationship between the scale of operations and efficiency. That is, large DMUs are just as efficient as small ones in converting inputs to outputs. Under constant returns to scale, input minimization and output maximization produce the same relative efficiency scores, provided inputs are controllable. On the other hand variable returns to scale means a rise in inputs is expected to result in a disproportionate rise in outputs. VRS is preferred when a significant correlation between DMU size and efficiency can be demonstrated in a large sample, therefore, broke down technical efficiency into pure technical efficiency and scale efficiency and measured its efficiency and returns to scale.

Efficiency in DEA: Consider $\mathrm{n}$ decision making units, One DMU receives inputs and changes them to outputs. The $\mathrm{y}_{\mathrm{rj}}, \mathrm{x}_{\mathrm{ij}}>0$ in the model are constant which represent amounts of $\mathrm{r}^{\text {th }}$ output $(\mathrm{r}=1,2, \ldots, \mathrm{s})$ and the $\mathrm{i}^{\text {th }}$ input $(\mathrm{i}=$ $1,2, \ldots, \mathrm{m})$ of the $\mathrm{j}^{\text {th }}$ Decision Making Unit $\left(\mathrm{DMU}_{\mathrm{j}}\right)$ which $\mathrm{j}=1,2, \ldots, \mathrm{n}$. therefore, each observed DMU is characterized by a pair of non-negative input and output vectors $\left(X_{j}, Y_{j}\right) \in R^{m+s}, j \in\{1,2, \ldots, n\}$. The classic DEA model assumes that the underlying production possibility set denoted by:

$\mathrm{T}=\left\{\mathrm{X}, \mathrm{Y} \mid \mathrm{X} \in \mathrm{R}_{+}^{\mathrm{m}}\right.$ can produce $\left.\mathrm{Y} \in \mathrm{R}_{+}^{\mathrm{s}}\right\}$

The production possibility sets corresponding to CRS and VRS technologies are:

$\mathrm{T}_{\mathrm{CRS}}=\left\{\left(\mathrm{X}_{\mathrm{j}}, \mathrm{Y}_{\mathrm{j}}\right) \mid \exists \lambda=\left(\lambda_{1}, \lambda_{2}, \ldots ., \lambda_{\mathrm{n}}\right), \lambda_{\mathrm{j}} \geq 0 \forall \mathrm{j}, \lambda \mathrm{Y} \geq \mathrm{Y}_{\mathrm{j}}, \lambda \mathrm{X} \leq \mathrm{X}_{\mathrm{j}}\right\}$
$\mathrm{T}_{\mathrm{VRS}}=\left\{\left(\mathrm{X}_{\mathrm{j}}, \mathrm{Y}_{\mathrm{j}}\right) \mid \exists \lambda=\left(\lambda_{1}, \lambda_{2}, \ldots . ., \lambda_{\mathrm{n}}\right), \lambda_{\mathrm{j}} \geq 0 \forall \mathrm{j}, \lambda \mathrm{X} \leq \mathrm{X}_{\mathrm{j}}, \lambda \mathrm{Y} \geq \mathrm{Y}_{\mathrm{j}}, \sum_{\mathrm{j}=1}^{\mathrm{n}} \lambda_{\mathrm{j}}=1\right\}$

We now turn to efficiency estimation of DMUs. For brevity, we here restrict attention to the classic Farrell output efficiency measure, defined as:

Efficiency $=\varphi^{*}=\max \{\varphi \mid(X, \varphi \mathrm{Y}) \mathrm{T}\}$ 
In order to assess the relative performance of the existing DMU (the observed unit is generally called $\left.\mathrm{DMU}_{\mathrm{o}}, \mathrm{o} \in\{1,2, \ldots, \mathrm{n}\}\right)$ in this CRS scenario and assuming an output orientation, the CCR development model is following: (Charnes et al., 1987) Eq. 1:

$$
\varphi_{0}^{*}=\max \varphi_{0}
$$

$$
\begin{aligned}
& \text { S.t. } \quad \sum_{\mathrm{j}=1}^{\mathrm{n}} \lambda_{\mathrm{j}} \mathrm{y}_{\mathrm{rj}} \leq \mathrm{x}_{\mathrm{io}} \quad \mathrm{i}=1,2, \ldots, \mathrm{m} \\
& \sum_{\mathrm{j}=1}^{\mathrm{n}} \lambda_{\mathrm{j}} \mathrm{y}_{\mathrm{rj}} \geq \varphi \mathrm{y}_{\mathrm{ro}} \quad \mathrm{r}=1,2, \ldots, \mathrm{s} \\
& \lambda_{\mathrm{j}} \geq 0 \quad \mathrm{j}=1,2, \ldots, \mathrm{n}
\end{aligned}
$$

The efficiency in VRS model obtains with addition $\sum_{\mathrm{j}=1}^{\mathrm{n}} \lambda_{\mathrm{j}}=1$ to model (1) (Banker et al., 1984).

Definition 1: If $\varphi_{0}^{*}$ be the optimal value of evaluating $\mathrm{DMU}_{\mathrm{o}}$, then $\mathrm{DMU}_{\mathrm{o}}$ is called (strong) efficient if and only if $\varphi_{0}^{*}=1$ and all slack variables be zero in all optimal solutions of model (1).

Definition 2 (Efficiency): $\mathrm{DMU}_{\mathrm{o}}$ is efficient if and only if it is not possible to improve some inputs or outputs without worsening other inputs or outputs (Cooper et al., 2001).

Definition 3 (Technical inefficiency): $\mathrm{DMU}_{\mathrm{o}}$ is inefficient when it is possible to improve some inputs or outputs without worsening any other inputs or outputs.

Congestion and radial measure approach (FGL): The FGL approach proceeds in two stages. The first stage uses an "output-oriented" model as follows Eq. 2:

$$
\beta_{o}^{*}=\max \beta_{o}
$$

S.t. $\quad \sum_{j=1}^{n} \lambda_{j} x_{i j} \leq \tau x_{i o} \quad i=1,2, \ldots, m$

$$
\begin{aligned}
& \sum_{j=1}^{n} \lambda_{j} y_{r j}=\beta y_{r o} \\
& 0 \leq \tau \leq 1, \quad \lambda_{j} \geq 0
\end{aligned}
$$

Compared with Model (1), a new decision variable $\tau$ which allows for proportional scaling of the convex combinations of the observed inputs and outputs spanning the production technology is introduced, also the other difference between models (1) and (2) is that output inequalities are changed into output equalities. The input congestion measures are then defined as:

$$
\mathrm{C}\left(\varphi_{\mathrm{o}}^{*}, \beta_{\mathrm{o}}^{*}\right)=\frac{\mathrm{o}_{\mathrm{o}}^{*}}{\beta_{\mathrm{o}}^{*}}
$$

If $\mathrm{C}\left(\varphi_{0}^{*}, \beta_{\mathrm{o}}^{*}\right)=1$, then input is not congested; alternatively, if $C\left(\varphi_{0}^{*}, \beta_{0}^{*}\right)>1$ then congestion is present.

Basically, Models (1) and (2) differ only in the first set of constraints. When there is only one input, the input constraint in Model (1), " $\sum_{\mathrm{j}=1}^{\mathrm{n}} \lambda_{\mathrm{j}} \mathrm{x}_{\mathrm{ij}}+\mathrm{S}^{-}=\mathrm{x}_{\mathrm{io}}$ " can always be replaced by " $\sum_{\mathrm{j}=1}^{\mathrm{n}} \lambda_{\mathrm{j}} \mathrm{x}_{\mathrm{ij}} \leq \tau \mathrm{x}_{\mathrm{io}}, 0 \leq \tau \leq 1$ ", which is the input constraint of Model (2) (Kao, 2010).

Congestion and Slacks (CCT): This alternate approach also proceeds in a two-stage manner with the following "output oriented" model used in the first stage Eq. 3:

$$
\begin{array}{ll}
\operatorname{Max} \phi_{o}+\varepsilon\left(\sum_{r=1}^{s} s_{r}^{+}+\sum_{i=1}^{m} s_{i}^{-}\right) & \\
\text {s.t. } x_{i 0}=\sum_{j=1}^{n} x_{i j} \lambda_{j}+s_{i}^{-} & i=1,2, \ldots, m \\
\phi_{0} y_{r o}=\sum_{j=1}^{n} y_{r i} \lambda_{j}-s_{r}^{+} & r=1,2, \ldots, s \\
1=\sum_{j=1}^{n} \lambda_{j} & \\
\lambda_{j}, s_{r}^{+}, s_{i}^{-} \geq 0 \quad j=1, \ldots, n ; i=1, \ldots, m ; r=1, \ldots, s .
\end{array}
$$

Inefficiency is a necessary condition for the presence of congestion. Therefore, first use (3) to identify whether $\mathrm{DMU}_{0}$ is inefficient. For an optimal solution $\left(\varphi_{0}^{*}, \lambda^{*}, \mathrm{~S}^{-*} \mathrm{~S}^{+*}\right)$ of (3), If found to be inefficient, utilize the "CCR projection formulas" to form the following model Eq. 4:

$$
\begin{aligned}
& \max \sum_{i=1}^{m} \delta_{i} \\
& \text { s.t. } x_{i o}-s_{i}^{-*}=\sum_{j=1}^{n} x_{i j} \lambda_{j}-\delta_{i} \quad i=1,2, \ldots, m \\
& \varphi_{o}^{*} y_{r o}+s_{r}^{+^{*}}=\sum_{j=1}^{n} y_{r j} \lambda_{j} \quad r=1,2, \ldots, s \\
& 1=\sum_{j=1}^{n} \lambda_{j} \\
& S_{i}^{-} \geq \delta_{i} \quad i=1,2, \ldots, m \\
& \lambda_{j}, \delta_{i} \geq 0 \quad j=1, \ldots, n ; i=1, \ldots, m ; r=1, \ldots, s
\end{aligned}
$$




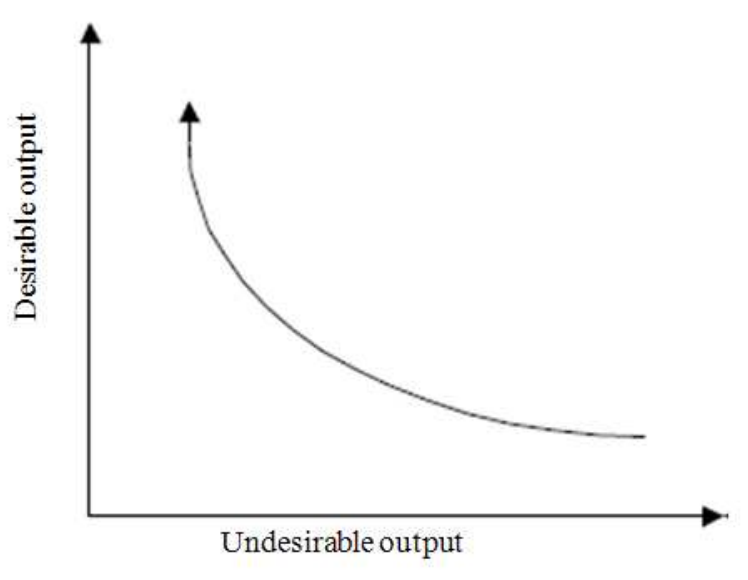

Fig. 1: The desirable output against undesirable output

Finally, to determine the amount of congestion:

$\mathrm{C}_{\mathrm{i}}^{*}=\mathrm{S}_{\mathrm{i}}^{*}-\delta_{\mathrm{i}}^{*} \quad \mathrm{i}=1,2, \ldots, \mathrm{m}$

Where:

$\delta_{\mathrm{i}}^{*}=$ Obtained from (4)

$\mathrm{C}_{\mathrm{i}}^{*}=$ Then the "congesting amount" in the "total slack" associated with $S_{i}^{-}$in input $i=1, \ldots, m$, as obtained from (4)

$\delta_{\mathrm{i}}^{*}=$ The (maximum) amount of this total slack that can be assigned to "purely technical" (noncongesting) inefficiency, as obtained from (4)

Undesirable output in DEA: The general practice in performance and production efficiency measurement has been to ignore additional products of most transformation processes that can be classified as "undesirable" outputs. Undesirable outputs are often produced jointly with desirable output; good output cannot be produced without producing some bad output.

Suppose the DEA data domain is expressed as $\mathrm{X}$ as inputs and $\left(\mathrm{Y}^{\mathrm{g}}, \mathrm{Y}^{\mathrm{b}}\right)$ as outputs, where $\mathrm{Y}^{\mathrm{g}}$ and $\mathrm{Y}^{\mathrm{b}}$ represent the desirable (good) and undesirable (bad) outputs, respectively. Obviously, we wish to increase the $\mathrm{Y}^{\mathrm{g}}$ and to decrease the $\mathrm{Y}^{\mathrm{b}}$ to improve the performance. However, in the standard BCC model (1), both $\mathrm{Y}^{\mathrm{g}}$ and $\mathrm{Y}^{\mathrm{b}}$ are supposed to increase to improve the performance. In order to increase the desirable outputs and to decrease the undesirable outputs, Fare et al. (1989) modify the model (3) into the following nonlinear programming problem Eq. 5:

$\max \varphi_{0}$

$$
\begin{array}{ll}
\text { s.t. } \mathrm{x}_{\mathrm{io}} \geq \sum_{\mathrm{j}=1}^{\mathrm{n}} \mathrm{x}_{\mathrm{ij}} \lambda_{\mathrm{j}} & \mathrm{i}=1,2, \ldots, \mathrm{m} \\
\phi_{\mathrm{o}} \mathrm{y}_{\mathrm{ro}}^{\mathrm{g}} \leq \sum_{\mathrm{j}=1}^{\mathrm{n}} \mathrm{y}_{\mathrm{rj}}^{\mathrm{g}} \lambda_{\mathrm{j}} & \forall \mathrm{r} \in \mathrm{G} \\
\frac{1}{\phi_{\mathrm{o}}} \mathrm{y}_{\mathrm{ro}}^{\mathrm{b}} \leq \sum_{\mathrm{j}=1}^{\mathrm{n}} \mathrm{y}_{\mathrm{rj}}^{\mathrm{b}} \lambda_{\mathrm{j}} & \forall \mathrm{r} \in \mathrm{B} \\
1=\sum_{\mathrm{j}=1}^{\mathrm{n}} \lambda_{\mathrm{j}} & \\
\lambda_{\mathrm{j}} \geq 0 \quad \mathrm{j}=1, \ldots, \mathrm{n} .
\end{array}
$$

Where:

$\mathrm{G}=$ Set of good outputs

$\mathrm{B}=$ Undesirable outputs

This model allowed the desirable outputs to increase by some proportion and at the same time allowed the undesirable outputs to decrease by the same proportion. The result was a northwesterly hyperbolic path as shown in the Fig. 1.

However, in the case of the hyperbolic path, the efficiency measure makes sure that as the desirable output increases, the undesirable output decreases. This is incorporated into the model in such a way that both the outputs change by the same proportion but in different directions.

The model (5) is nonlinear, in order to linearization, first we multiply each undesirable output constraint by $\varphi$ and then apply changing variable as $\lambda_{j} \varphi=\gamma_{j}$; therefore model (5) convert to linear program as following Eq. 6:

$\max \varphi_{\text {。 }}$

s.t. $\mathrm{x}_{\mathrm{i} o} \geq \sum_{\mathrm{j}=1}^{\mathrm{n}} \mathrm{x}_{\mathrm{ij}} \lambda_{\mathrm{j}} \quad \mathrm{i}=1,2, \ldots, \mathrm{m}$

$\varphi_{0} \mathrm{y}_{\mathrm{r}}^{\mathrm{g}} \leq \sum_{\mathrm{j}=1}^{\mathrm{n}} \mathrm{y}_{\mathrm{ri}}^{\mathrm{g}} \lambda_{\mathrm{j}} \quad \forall \mathrm{r} \in \mathrm{G}$

$\mathrm{y}_{\mathrm{ro}}^{\mathrm{b}} \leq \sum_{\mathrm{j}=1}^{\mathrm{n}} \mathrm{y}_{\mathrm{rj}}^{\mathrm{b}} \gamma_{\mathrm{j}} \quad \forall \mathrm{r} \in \mathrm{B}$

$1=\sum_{j=1}^{n} \lambda_{j}$

$\varphi_{\mathrm{o}}=\sum_{\mathrm{j}=1}^{\mathrm{n}} \gamma_{\mathrm{j}}$

$\lambda_{\mathrm{j}}, \gamma_{\mathrm{j}} \geq 0 \mathrm{j}=1, \ldots, \mathrm{n}$ 
Am. J. Applied Sci., 8 (9): 903-909, 2011

Table 1: inputs and outputs

\begin{tabular}{lrrrrrrr}
\hline DMU & \multicolumn{1}{c}{$\mathrm{x}_{1}$} & $\mathrm{x}_{2}$ & \multicolumn{1}{c}{$\mathrm{x}_{3}$} & $\mathrm{y}_{1}$ & $\mathrm{y}_{2}$ & \multicolumn{1}{c}{$\mathrm{y}_{3}$} & $\mathrm{y}_{4}$ \\
\hline 1 & 433 & 5 & 88 & 56 & 1 & 45 & 15 \\
2 & 242 & 1 & 55 & 35 & 2 & 10 & 8 \\
3 & 233 & 2 & 38 & 46 & 6 & 40 & 7 \\
4 & 406 & 1 & 65 & 51 & 6 & 0 & 12 \\
5 & 989 & 10 & 140 & 75 & 2 & 60 & 18 \\
6 & 1276 & 9 & 145 & 148 & 2 & 60 & 22 \\
7 & 2190 & 6 & 165 & 189 & 2 & 20 & 25 \\
8 & 634 & 6 & 82 & 68 & 4 & 40 & 18 \\
9 & 757 & 4 & 78 & 103 & 2 & 10 & 12 \\
10 & 650 & 12 & 64 & 25 & 2 & 130 & 20 \\
11 & 525 & 6 & 90 & 43 & 8 & 120 & 21 \\
12 & 1020 & 2 & 100 & 116 & 1 & 0 & 24 \\
13 & 1718 & 11 & 140 & 111 & 4 & 50 & 24 \\
14 & 1025 & 6 & 120 & 80 & 3 & 90 & 17 \\
15 & 655 & 11 & 88 & 30 & 10 & 50 & 16 \\
16 & 924 & 5 & 92 & 39 & 1 & 20 & 21 \\
17 & 360 & 6 & 72 & 31 & 1 & 20 & 10 \\
18 & 779 & 8 & 102 & 146 & 1 & 10 & 14 \\
19 & 589 & 5 & 92 & 115 & 1 & 0 & 15 \\
20 & 441 & 4 & 80 & 35 & 1 & 20 & 13 \\
21 & 258 & 5 & 50 & 11 & 1 & 20 & 12 \\
\hline
\end{tabular}

Note that (6) expands desirable outputs and contracts undesirable outputs as in the non-linear DEA model (5).

If $\left(\varphi^{*}{ }_{\mathrm{o}}, \lambda^{*}, \mathrm{~S}^{-*}, \mathrm{~S}^{+^{*}}\right)$ is optimal solution of $(6)$ and it is inefficient, then for calculating the congestion, we must compute model (7) Eq. 7:

$$
\begin{aligned}
& \max \quad \sum_{i=1}^{m} \delta_{i} \\
& \begin{array}{l}
\text { s.t. } x_{i o}-s_{i}^{-*}=\sum_{j=1}^{n} x_{i j} \lambda_{j}-\delta_{i} \quad i=1,2, \ldots, m \\
\varphi_{o}^{*} y_{r o}+s_{r}^{+^{*}}=\sum_{j=1}^{n} y_{r j} \lambda_{j}
\end{array} \\
& \begin{array}{l}
y_{r o}^{b}+s_{r}^{+^{*}}=\sum_{j=1}^{n} y_{r j}^{b} \gamma_{j} \\
1=\sum_{j=1}^{n} \lambda_{j}
\end{array} \\
& \phi=\sum_{j=1}^{n} \gamma_{j} \in G \in B \\
& S_{i}^{-*} \geq \delta_{i} \\
& \lambda_{j}, \gamma_{j}, \delta_{i} \geq 0 \quad j=1,2, \ldots, m
\end{aligned}
$$

Case study: Congestion in the universities: The application of DEA to universities has generally focused on the efficiencies of university programs or departments. In this article, the Sistan and Baluchestan University's educational departments are viewed as DMUs. Input and output variables were chosen after consultation with the management.
Input variables included the number of registered student (x1) and the number of teaching staff (x2) and Guest lecturer's number of units (x3). Four output variables were selected to represent both teaching and research outcomes: the number of graduates (y1), the number of passed students to higher levels (y2) and the performed research work (y3) and dropout students (y4), which dropout students is undesirable output. Our original data consist of the annual statistics for the year 2009 collected in each of the 21 departments of the university. From these data the outputs and inputs are as shown in Table 1.

\section{RESULTS}

We performed the model CCT with undesirable output, model (6) and (7) and then solved them using the DEA-Solver and LINGO software. Table 2 is a summary of the efficiency scores and congestion of inputs and undesirable output. These efficiency scores represent the best possible efficiency attainable by a DMU given its inputs and outputs and comparing it to the inputs and outputs of the remaining DMUs.

\section{DISCUSSION}

As we can observe, thirteen DMUs are efficient. The inefficient DMUs have congestion in the all or some inputs but all they have congestion in undesirable output.

Determining how much of the congestion inefficiency was due to excess use of inputs and exist undesirable output and found that $100 \%$ of inefficiency was due to the congestion effect.

The last row in Table 2 indicates the correlation between the efficiency of the units with the congestion of inputs and undesirable output. These correlations vary between 0.105 until 0.932 . There is significant correlation between dropout students and efficiency (0.932) while there is no correlation between inefficiency and congestion inputs. This fact reveals that the key factor of their inefficiency is the indicator undesirable output. Table 3 indicates congestion each inputs and undesirable output ratio its own indicators. The results show strangely correlation between undesirable output and inefficiency. 
Am. J. Applied Sci., 8 (9): 903-909, 2011

Table 2: Congestion of indicators

\begin{tabular}{llclrr}
\hline DMU & Score & Congestion of $\mathrm{x}_{1}$ & Congestion of $\mathrm{x}_{2}$ & Congestion of $\mathrm{x}_{3}$ & Congestion of $\mathrm{y}_{4}$ \\
\hline 1 & 1.209 & 0.000 & 0.593 & 21.858 & 5.858 \\
2 & 1.000 & 0.000 & 0.000 & 0.000 & 0.000 \\
3 & 1.000 & 0.000 & 0.000 & 0.000 & 0.000 \\
4 & 1.000 & 0.000 & 0.000 & 17.306 & 0.000 \\
5 & 1.406 & 17.571 & 2.217 & 0.000 & 3.706 \\
6 & 1.000 & 0.000 & 0.000 & 0.000 & 0.000 \\
7 & 1.000 & 0.000 & 0.000 & 0.000 & 0.000 \\
8 & 1.240 & 0.000 & 0.377 & 0.000 & 7.982 \\
9 & 1.000 & 0.000 & 0.000 & 0.000 & 0.000 \\
10 & 1.000 & 0.000 & 0.000 & 0.000 & 0.000 \\
11 & 1.000 & 0.000 & 0.000 & 0.000 & 0.000 \\
12 & 1.000 & 0.000 & 0.000 & 0.224 & 0.000 \\
13 & 1.150 & 211.306 & 4.717 & 0.000 & 4.553 \\
14 & 1.000 & 0.000 & 0.000 & 0.000 & 0.000 \\
15 & 1.000 & 0.000 & 0.000 & 17.549 & 0.000 \\
16 & 2.480 & 63.496 & 0.000 & 0.000 & 36.161 \\
17 & 2.074 & 0.000 & 2.535 & 0.000 & 0.000 \\
18 & 1.000 & 0.000 & 0.000 & 16.582 & 0.000 \\
19 & 1.000 & 0.000 & 0.000 & 7.548 & 1.207 \\
20 & 2.087 & 0.000 & 0.000 & 0.473 & 0.932 \\
21 & 2.342 & 0.000 & 2.658 & 0.344 & \\
Correlation & & 0.105 & & & \\
\hline
\end{tabular}

Table 3: Relation between efficiency and congestions

\begin{tabular}{lllll}
\hline & Congestion of $\mathrm{x} 1 / \mathrm{x} 1$ & Congestion of $\mathrm{x} 2 / \mathrm{x} 2$ & Congestion of $\mathrm{x} 3 / \mathrm{x} 3$ & Congestion of $\mathrm{y} 4 / \mathrm{y} 4$ \\
\hline Average & 0.009975 & 0.08505 & 0.048497 & 0.330675 \\
Correlation & 0.22708 & 0.51388 & 0.583026 & 0.988757 \\
\hline
\end{tabular}

\section{CONCLUSION}

The main thrust of this study is to measure congestion in inputs and undesirable outputs in DEA, because increasing undesirable output can decries desirable outputs. A model is proposed in this study which it has two characteristics: it allows for studying congestion in a sample of departments' university, it conveniently considers congestion in undesirable output in addition to congestion inputs. Also having examined the trends in congestion and its effect on inefficiency, we can attempt to unravel its underlying causes. This study investigates effective of undesirable outputs on the inefficiency, viewpoint congestion. In particular, why should a rise in each inputs cause a fall in output? By contrast, a rise in the number of registered student $\left(\mathrm{x}_{1}\right)$, with academic staffing $\left(\mathrm{x}_{2}\right)$ and other resources held constant, could well lead to a fall in output in terms of research and consultancy. This is because the extra students would be competing for scarce staff time. There would be additional costs in terms of assessment, supervision. On the other hand extra postgraduate students could be helpful in terms of stimulating research output. As regards undergraduate students, output in terms of qualifications research could decline with an increase in the number of undergraduates because staff would be unable to devote the same amount of time to each student as before. Also dropout students imply to fall other outputs, instance the number of graduates $\left(\mathrm{y}_{1}\right)$, the number of passed students to higher levels $\left(\mathrm{y}_{2}\right)$, therefore, congestion in undesirable output decrease other outputs and imply lower efficiency.

\section{REFERENCES}

Ashrafi, A., A.B. Jaafar, M.R.A. Bakar and L.S. Lee, 2011. The efficiency measurement of parallel production systems: A non-radial data envelopment analysis model. J. Com. Sci., 7: 749-756. DOI: 10.3844/jcssp.2011.749.756

Banker, R.D., A. Charnes and W.W. Cooper, 1984. Some models for estimating technical and scale inefficiencies in data envelopment analysis. Manage. Sci., 30: 1078-1092. DOI: 10.1287/mnsc.30.9.1078

Charnes, A., W.W. Cooper and E. Rhodes, 1978. Measuring the efficiency of decision making units, Eur. J. Operat. Res., 2: 429-444. DOI: 10.1016/0377-2217(78)90138-8

Chen, T.H., C.P. Bao, C.M. Huang and I.C. Wang, 2010. Efficiency decomposition with enhancing Russell measure in data envelopment analysis. Am. J. Applied Sci., 7: 438-441. DOI: 10.3844/ajassp.2010.438.441 
Cooper, W.W., H. Deng, B. Gu, S. Li and R.M. Thrall, 2001. Using DEA to improve the management of congestion in Chinese industries (1981-1997). Socio-Econo. Plann. Sci., 35: 227-242. DOI: 10.1016/S0038-0121(01)00005-2

Farrell, M.J., 1957. The measurement of productive efficiency. J. Royal Stat. Soc. Series A, 120: 253290.

Fare, R., S. Grosskopf and C.A.K. Lovell, 1986. Scale economies and duality. J. Econ., 46: 175-182. DOI: 10.1007/BF01229228

Fare, R., S. Grosskopf, C.A.K. Lovell and C. Pasurka, 1989. Multilateral productivity comparisons when some outputs are undesirable: A nonparametric approach. Rev. Econ. Stat., 71: 90-98.

Jahanshahoo, G.R., J. Vakili and S.M. Mirdehgan, 2011. An approach using a branch-and-bound algorithm for evaluating the performance of inefficient DMUs in DEA. J. Applied Sci., 11: 450461. DOI: $10.3923 /$ jas.2011.450.461

Kao, C., 2010. Congestion measurement and elimination under the framework of data envelopment analysis. Int. J. Produ. Econ., 123: 257-265. DOI: 10.1016/j.ijpe.2009.06.044
Rayeni, M.M., G. Vardanyan and F.H. Saljooghi, 2010. The measurement of productivity growth in the academic departments using malmquist productivity index. J. Applied Sci., 10: 2875-2880. DOI: $10.3923 /$ jas.2010.2875.2880

Rayeni, M.M. and F.H. Saljooghi, 2010. Network data envelopment analysis model for estimating efficiency and productivity in universities. J. Comp. Sci., 6: 1252-1257. DOI: 10.3844 jcssp.2010.1252.1257

Scheel, H., 2001. Undesirable outputs in efficiency valuations. Eur. J. Operat. Res., 132: 400-410. DOI: 10.1016/S0377-2217(00)00160-0

Taher, S.A. and H. Besharat, 2008. Transmission congestion management by determining optimal location of FACTS devices in deregulated power systems. Am. J. Applied Sci., 5: 242-247. DOI: 10.3844/ajassp.2008.242.247 